\title{
CZU:634.51:575.8(478) \\ https://doi.org/10.53040/gppb7.2021.68 \\ CERCETĂRI PRIVIND DIVERSITATEA GENOFONDULUI NUCULUI (Juglans regia L.) ÎN REPUBLICA MOLDOVA
}

\author{
Pîntea Marial, Cozmic Radu ${ }^{1}$, Mapelli Sergio ${ }^{2}$ \\ ${ }^{1}$ Inst. Științifico-Practic de Horticultură și Tehnologii Alimentare, Chișinău,Republica Moldova \\ ${ }^{2}$ Institutul de Biologie și Biotehnologie Agrară, Milan, Italia \\ e-mail: mariapintea@yandex.ru
}

\begin{abstract}
In the article there are presented some results of morphological and ecological researches of walnut (Juglans regia L.) genotypes, selected in different pomological zone of Rep. Moldova. Obtained data shows manifestation of different characteristics like flowering period, dichogamous types, manifestation of capacity to develop pistillate flowers from lateral buds, as well as capacity of formation of fruits from lateral buds.
\end{abstract}

Key words: walnut, dichogamy, local biotypes, diversity, genfond conservation, Republic of Moldova

\section{Introducere}

Nucul (Juglans regia L.), care pînă nu demult în Republica Moldova era multiplicat în special prin seminţe, de asemenea şi răspîndit spontan înglobează o diversitate imensă morfo- şi genotipică. În lucrarea prezentă pentru prima dată se ia în studiu biotipuri de proveniență seminală (polenizare liberă), fiind selectați din peste 140 probe (reprezentanţii cei mai valoroşi conform aprecierii productivității și calităților organoleptice a miezului ) din diferite zone pomicole ale ţării, utilizînd metodologii moderne, perfecţionate pentru nuc în Italia inclusiv marcajul molecular. Tot odată aceasta abordare permite de a compara variabilitatea genetică şi stabilirea posibilelor relaţii de co-evoluare genotipică. Este interesantă şi stabilirea calităţilor fructelor conform determinării componenţilor de bază a miezului de nucă: acizii graşi şi tocoferolii, care de asemenea s-a efectuat în premieră prin metodele moderne respective. Analizele concomitente a componenţilor de bază chimici ai miezului de nucă vor permite identificarea populaţiilor, care cantitativ se deosebesc în deplină concordanţă cu caracteristicile agro-ecologice. Evidenţierea diferitor calităţi ale nucilor permite selectarea de biotipuri preţioase-candidaţi la soiuri pentru diferite destinaţii de utilizare în industria alimentară etc. În diferite ţări $[2,3,7,8]$. Cel mai important lucru în direcţia depăşirii parametrilor de performanţă şi calitate se poate considera selectarea și implementarea genotipurilor de nuc evidențiate ce posedă plasticitate ecologică şi adaptabilitate largă la condiţiile de mediu $[3,7,8]$, capacitate de fructificare din mugurii laterali şi terminali, a genotipurilor cu dezmugurire și înflorire feminină foarte tardivă.

\section{Materiale și Metode}

Materialele, indicatorii de studiu au fost colectate și reprezentate de peste 140 probe din diferite zone pomicole ale Republicii Moldova (reprezentanţii cei mai valoroşi conform aprecierii preventive a productivității și calităților organoleptice a miezului) conform metodelor standard [4]. Perioada de înflorire, tipul de dihogamie, manifestarea capacității de formare a florilor din mugurii laterali, precum și capacitatea de formare a fructelor din mugurii laterali etc. au fost studiate conform descriptorilor UPOV [1].

\section{Rezultate și discutiii}

Studiile generale privind locaţiile de răspîndire a genotipurilor selectate ca de perspectivă după studiile preventive a caracteristicilor organoleptece ale miezului, perioada de înflorire, tipul de dihogamie, manifestarea capacității de formare a florilor din mugurii laterali precum și capacitatea de formare a fructelor din mugurii laterali (tab. 1, 2, fig. 1) au permis de a generaliza preventiv unele manifestări privind biologia florală și fructificarea nucului de proveniență seminală în diferite zone ale țării noastre. Astfel, printe biotipurile selectate tipurile de dihogamie protandru și protogin sunt reprezentate în proporții identice în toate zonele studiate. Înflorirea simultană se regăsește doar foarte rar în cadrul zonelor studiate. Același lucru se poate concluziona privind începutul înfloririi masculine și feminine, în zona de Nord fiind întârziate. Manifestarea capacității de formare a florilor din mugurii laterali, precum și capacitatea de formare 
a fructelor din mugurii laterali este mai pronunțată în zona de Centru, iar procentul legării fructelor la mugurii laterali a fost mai înalt la unele biotipuri din zona de Nord -Vest (tab. 1, 2).

Tabelul 1.Coordonatele (GPS) a locațiilor de răspândire a genotipurilor selectate ca de perspectivă (zona de Centru)

\begin{tabular}{|c|c|c|c|c|c|c|c|c|}
\hline \multirow[b]{2}{*}{ Genotipul } & \multicolumn{2}{|c|}{ Coordonatele, grade } & \multirow[b]{2}{*}{$\begin{array}{c}\text { Altitudi } \\
\text { nea, } m\end{array}$} & \multirow{2}{*}{$\begin{array}{l}\text { Înflorirea } \\
\text { feminine- } \\
\text { receptivitatea } \\
\text { max. pentru } \\
\text { polenizare }\end{array}$} & \multirow[b]{2}{*}{$\begin{array}{c}\text { Răspân- } \\
\text { direa } \\
\text { polenulu } \\
\text { i }\end{array}$} & \multirow{2}{*}{$\begin{array}{c}\text { Tipul } \\
\text { dihogamic: p/g- } \\
\text { protogin; } \\
\text { p/a-protandric, } \\
\text { simultan-sim }\end{array}$} & \multicolumn{2}{|c|}{ Capacități de fructificare laterală } \\
\hline & Latitudine & Longitudine & & & & & $\begin{array}{c}\% \text { formare a } \\
\text { florilor din } \\
\text { mugurii laterali }\end{array}$ & $\begin{array}{c}\text { Manifestarea } \\
\text { fructificării } \\
\text { laterale }\end{array}$ \\
\hline $1 \mathrm{C} \mathrm{md}$ & 47,170 & 28,429 & 89 & 28.04 & 17.04 & $\mathrm{p} / \mathrm{a}$ & 20,0 & 5,0 \\
\hline $3 \mathrm{C} \mathrm{md}$ & 47,080 & 28,180 & 86 & 02.05 & 07.05 & $\mathrm{p} / \mathrm{g}$ & 25,0 & 10,0 \\
\hline $4 \mathrm{C} \mathrm{md}$ & 47,254 & 28,318 & 135 & 26.04 & 16.04 & $\mathrm{p} / \mathrm{a}$ & 20,0 & 7,0 \\
\hline $5 \mathrm{C} \mathrm{md}$ & 47,340 & 28,533 & 151 & 26.04 & 05.05 & $\mathrm{p} / \mathrm{g}$ & 25,0 & 0,0 \\
\hline $7 \mathrm{C} \mathrm{md}$ & 47,632 & 28,818 & 230 & 28.04 & 15.04 & $\mathrm{p} / \mathrm{a}$ & 20,0 & 0,0 \\
\hline $8 \mathrm{C}$ md & 47,362 & 28,585 & 206 & 02.05 & 07.05 & $\mathrm{p} / \mathrm{g}$ & 25,0 & 6,0 \\
\hline 12C md & 47,404 & 28,199 & 126 & 28.04 & 16.04 & $\mathrm{p} / \mathrm{a}$ & 20,0 & 0,0 \\
\hline $13 \mathrm{C} \mathrm{md}$ & 47,250 & 28,318 & 147 & 02.05 & 07.05 & $\mathrm{p} / \mathrm{g}$ & 25,0 & 15,0 \\
\hline $14 \mathrm{C} \mathrm{md}$ & 47,097 & 28,685 & 88 & 22.04 & 02.05 & $\mathrm{p} / \mathrm{g}$ & 30,0 & 0,0 \\
\hline $16 \mathrm{C} \mathrm{md}$ & 46,940 & 28,785 & 99 & 02.05 & 27.04 & $\mathrm{p} / \mathrm{a}$ & 35,0 & 10,0 \\
\hline $17 \mathrm{C} \mathrm{md}$ & 46,570 & 28,810 & 230 & 06.05 & 22.04 & $\mathrm{p} / \mathrm{a}$ & 30,0 & 0,0 \\
\hline $18 \mathrm{C} \mathrm{md}$ & 46,708 & 28,880 & 72 & 02.05 & 23.04 & $\mathrm{p} / \mathrm{a}$ & 45,0 & 10,0 \\
\hline 19Cmd & 46,978 & 28,885 & 48 & 26.04 & 05.05 & $\mathrm{p} / \mathrm{g}$ & 30,0 & 0,0 \\
\hline 20C md & 46,960 & 28,840 & 230 & 22.05 & 02.05 & $\mathrm{p} / \mathrm{g}$ & 35,0 & 10,0 \\
\hline $21 \mathrm{C} \mathrm{md}$ & 46,874 & 28,811 & 67 & 29.04 & 18.04 & $\mathrm{p} / \mathrm{a}$ & 20,0 & 0,0 \\
\hline $22 \mathrm{C} \mathrm{md}$ & 46,994 & 28,382 & 172 & 05.05 & 10.05 & $\mathrm{p} / \mathrm{g}$ & 35,0 & 05,0 \\
\hline $23 \mathrm{C} \mathrm{md}$ & 46,950 & 28,715 & 180 & 02.05 & 18.04 & $\mathrm{p} / \mathrm{a}$ & 10,0 & 0,0 \\
\hline $24 \mathrm{C} \mathrm{md}$ & 46,870 & 28,615 & 235 & 02.05 & 07.05 & $\mathrm{p} / \mathrm{g}$ & 45,0 & 20,0 \\
\hline $25 \mathrm{C} \mathrm{md}$ & 46,752 & 28,705 & 199 & 26.04 & 15.04 & $\mathrm{p} / \mathrm{g}$ & 20,0 & 0,0 \\
\hline $26 \mathrm{C} \mathrm{md}$ & 46,809 & 28,417 & 214 & 01.05 & 07.05 & $\mathrm{p} / \mathrm{g}$ & 45,0 & 10,0 \\
\hline $33 \mathrm{C}$ md & 46,831 & 28,625 & 167 & 26.04 & 16.04 & $\mathrm{p} / \mathrm{a}$ & 30,0 & 0,0 \\
\hline $34 \mathrm{C} \mathrm{md}$ & 46,932 & 28,735 & 199 & 01.05 & 07.05 & $\mathrm{p} / \mathrm{g}$ & 25,0 & 15,0 \\
\hline $35 \mathrm{C}$ md & 46,920 & 28,712 & 123 & 27.04 & 18.04 & $\mathrm{p} / \mathrm{a}$ & 20,0 & 0,0 \\
\hline $36 \mathrm{C} \mathrm{md}$ & 46,944 & 28,516 & 167 & 03.05 & 09.05 & $\mathrm{p} / \mathrm{g}$ & 25,0 & 10,0 \\
\hline $38 \mathrm{C} \mathrm{md}$ & 46,960 & 28,725 & 95 & 28.04 & 12.04 & $\mathrm{p} / \mathrm{a}$ & 20,0 & 0,0 \\
\hline $39 \mathrm{C} \mathrm{md}$ & 46,942 & 28,430 & 224 & 01.05 & 09.05 & $\mathrm{p} / \mathrm{g}$ & 25,0 & 10,0 \\
\hline $40 \mathrm{Cmd}$ & 46,684 & 28,430 & 87 & 28.04 & 14.04 & $\mathrm{p} / \mathrm{a}$ & 50,0 & 10,0 \\
\hline 41Cmd & 46,920 & 28,717 & 109 & 03.05 & 08.05 & $\mathrm{p} / \mathrm{g}$ & 35,0 & 10,0 \\
\hline $42 \mathrm{C} \mathrm{md}$ & 46,826 & 28,810 & 128 & 26.04 & 01.05 & $\mathrm{p} / \mathrm{g}$ & 30,0 & 0,0 \\
\hline $43 \mathrm{C} \mathrm{md}$ & 46,965 & 28,610 & 72 & 01.05 & 06.05 & $\mathrm{p} / \mathrm{g}$ & 25,0 & 15,0 \\
\hline $44 \mathrm{C} \mathrm{md}$ & 46,730 & 28,789 & 109 & 27.04 & 19.04 & $\mathrm{p} / \mathrm{a}$ & 40,0 & 0,0 \\
\hline $45 \mathrm{C} \mathrm{md}$ & 46,828 & 28,582 & 142 & 01.05 & 07.05 & $\mathrm{p} / \mathrm{g}$ & 25,0 & 10,0 \\
\hline
\end{tabular}

\section{Concluzii}

Cercetările efectuate au permis de a evalua şi valorifica populaţii distincte de nuc în diferite zone pomicole şi de a selecta genotipuri unice conform caracteristicilor biologice şi de producţie. Conform caracteristicilor evidențiate se poate presupune că în zona pomologică de Centru se pot regăsi mai multe biotipuri importante pentru programele de ameliorare genetică a nucului.

Însuși continuitatea cercetărilor ține de promovarea şi recomandarea respective privind conservarea diversităţii genetice a speciei Juglans regia L. cu posibilitatea utilizării sustenabile pentru programe ameliorative, păstrarea resurselor naturale vizând schimbările globale de climă şi utilizare directă în producere. 
Tabelul 2.Coordonatele (GPS) locațiilor de răspândire a genotipurilor selectate ca de perspectivă (zonele Nord și Nord-Vest)

\begin{tabular}{|c|c|c|c|c|c|c|c|c|}
\hline \multirow[b]{2}{*}{ Genotipul } & \multicolumn{2}{|c|}{ Coordonatele, grade } & \multirow[b]{2}{*}{$\begin{array}{c}\text { Altitudin } \\
\text { ea, m }\end{array}$} & \multirow[b]{2}{*}{$\begin{array}{c}\text { Receptivitatea } \\
\text { maximă pentru } \\
\text { polenizare }\end{array}$} & \multirow[b]{2}{*}{$\begin{array}{c}\text { Răspândirea } \\
\text { polenului }\end{array}$} & \multirow{2}{*}{$\begin{array}{c}\text { Tipul dihogamic: } \\
\text { p/g-protogin; } \\
\text { p/a-protandric, } \\
\text { sim-simultan }\end{array}$} & \multicolumn{2}{|c|}{ Capacități de fructificare laterală } \\
\hline & Latitudine & Longitudine & & & & & $\begin{array}{c}\% \text { formare a } \\
\text { florilor din } \\
\text { mugurii laterali }\end{array}$ & $\begin{array}{l}\text { Manifestarea } \\
\text { fructificării } \\
\text { laterale }\end{array}$ \\
\hline $13 \mathrm{~N}$ md & 48,239 & 27,559 & 166 & 27.04 & 19.04 & $\mathrm{p} / \mathrm{a}$ & 10,0 & 0,0 \\
\hline $15 \mathrm{~N}$ md & 48,117 & 27,803 & 230 & 08.05 & 09.05 & $\mathrm{Sim} / \mathrm{p} / \mathrm{g}$ & 20,0 & 10,0 \\
\hline $16 \mathrm{~N} \mathrm{md}$ & 48,044 & 27,615 & 141 & 30.04 & 05.05 & $\mathrm{p} / \mathrm{g}$ & 30,0 & 05,0 \\
\hline $18 \mathrm{~N}$ md & 48,110 & 27,802 & 230 & 27.04 & 07.05 & $\mathrm{p} / \mathrm{g}$ & 25,0 & 10,0 \\
\hline $19 \mathrm{~N}$ md & 48,044 & 27,615 & 161 & 26.04 & 10.05 & $\mathrm{p} / \mathrm{a}$ & 25,0 & 0,0 \\
\hline $20 \mathrm{~N}$ md & 48,310 & 27,467 & 249 & 09.05 & 28.04 & $\mathrm{p} / \mathrm{a}$ & 0,0 & 0,0 \\
\hline $22 \mathrm{~N}$ md & 48,332 & 27,521 & 275 & 14.05 & 25.04 & $\mathrm{p} / \mathrm{a}$ & 30,0 & 0,0 \\
\hline $23 \mathrm{~N}$ md & 48,112 & 27,808 & 210 & 01.05 & 08.05 & $\mathrm{p} / \mathrm{g}$ & 15,0 & 10,0 \\
\hline $25 \mathrm{~N} \mathrm{md}$ & 48,009 & 27,605 & 140 & 26.04 & 15.04 & $\mathrm{p} / \mathrm{g}$ & 22,0 & 0,0 \\
\hline $26 \mathrm{~N} \mathrm{md}$ & 48,110 & 27,704 & 211 & 28.04 & 06.05 & $\mathrm{p} / \mathrm{g}$ & 22,0 & 10,0 \\
\hline $27 \mathrm{~N}$ md & 48,044 & 27,615 & 166 & 24.04 & 05.05 & $\mathrm{p} / \mathrm{g}$ & 0,0 & 0,0 \\
\hline $28 \mathrm{~N}$ md & 48,308 & 27,808 & 207 & 26.04 & 04.05 & $\mathrm{p} / \mathrm{g}$ & 45,0 & 20,0 \\
\hline $29 \mathrm{Nmd}$ & 48,044 & 27,615 & 146 & 04.05 & 25.04 & $\mathrm{p} / \mathrm{a}$ & 0,0 & 0,0 \\
\hline 30Nmd & 48,117 & 27,800 & 152 & 02.05 & 07.05 & $\mathrm{p} / \mathrm{g}$ & 25,0 & 10,0 \\
\hline 31Nmd & 48,044 & 27,615 & 166 & 26.04 & 15.04 & $\mathrm{p} / \mathrm{a}$ & 30,0 & 05,0 \\
\hline 32Nmd & 48,117 & 27,808 & 230 & 01.05 & 10.05 & $\mathrm{p} / \mathrm{g}$ & 25,0 & 15,0 \\
\hline 33Nmd & 48,044 & 27,615 & 166 & 29.04 & 19.04 & $\mathrm{p} / \mathrm{a}$ & 20,0 & 0,0 \\
\hline $1 \mathrm{NW}$ & 47,342 & 27,751 & 172 & 07.05 & 24.04 & $\mathrm{p} / \mathrm{a}$ & 0,0 & 0,0 \\
\hline $2 \mathrm{NW}$ & 47,569 & 27,430 & 151 & 29.04 & 02.05 & $\mathrm{p} / \mathrm{g}$ & 20,0 & 0,0 \\
\hline 3 NW & 47,407 & 27,903 & 135 & 08.05 & 09.05 & p/g-sim & 28,0 & 10,0 \\
\hline $4 \mathrm{NW}$ & 47,489 & 27,876 & 170 & 29.04 & 05.05 & $\mathrm{p} / \mathrm{g}$ & 30,0 & 15,0 \\
\hline $5 \mathrm{NW}$ & 47,248 & 27,651 & 155 & 04.05 & 08.05 & $\mathrm{p} / \mathrm{g}$ & 25,0 & 5,0 \\
\hline $6 \mathrm{NW}$ & 47,160 & 27,707 & 169 & 07.05 & 27.04 & $\mathrm{p} / \mathrm{a}$ & 20,0 & 0,0 \\
\hline $9 \mathrm{NW}$ & 47,436 & 27,524 & 114 & 27.04 & 03.05 & $\mathrm{p} / \mathrm{g}$ & 25,0 & 10,0 \\
\hline $10 \mathrm{NW}$ & 47,377 & 27,569 & 120 & 25.04 & 17.04 & $\mathrm{p} / \mathrm{a}$ & 30,0 & 0,0 \\
\hline $11 \mathrm{NW}$ & 47,242 & 27,419 & 138 & 02.05 & 28.04 & $\mathrm{p} / \mathrm{a}$ & 65,0 & 50,0 \\
\hline $12 \mathrm{NW}$ & 47,569 & 27,575 & 140 & 26.04 & 05.05 & $\mathrm{p} / \mathrm{g}$ & 70,0 & 45,0 \\
\hline $13 \mathrm{NW}$ & 47,994 & 29,011 & 63 & 02.05 & 06.05 & $\mathrm{p} / \mathrm{g}$ & 35,0 & 10,0 \\
\hline
\end{tabular}
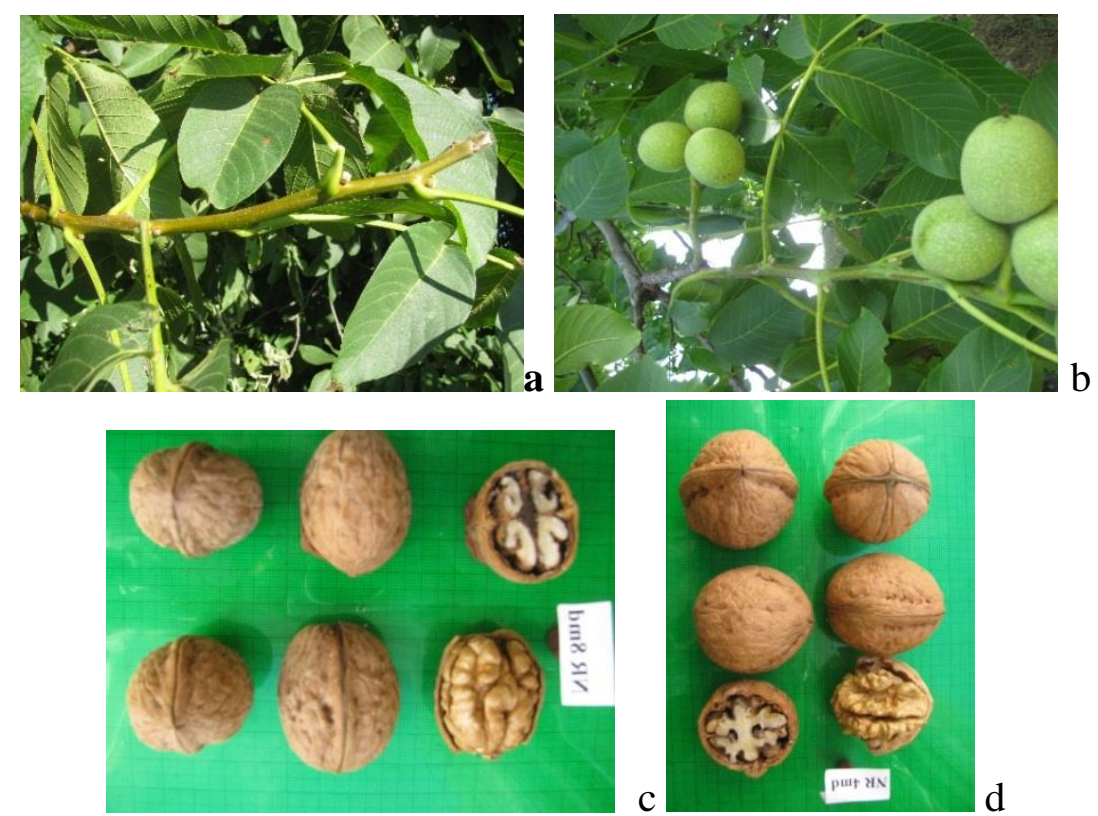

Fig.1.Fructificare laterală: a- muguri de rod, b-fructe. Genotipuri performante -c, d 


\section{Bibliografie}

1. ANONYMOUS. 1999. Guidelines for the conduct of tests for distinctness, uniformity and stability. Walnut (Juglans regia L.). International Union for the Protection of New Varieties of Plants (UPOV) TG/125/6, Geneva, Switzerland, $34 \mathrm{p}$

2. BUJDOSÓ, G., IZSÉPI, F., SZÜGYINÉ BARTHA, K., VARJAS, V. AND SZENTIVÁNYI, P. 2020. Persian walnut breeding program at Naric Fruticulture Research Institute in Hungary. Acta Hortic. 1280, 8994. DOI: 10.17660/ActaHortic.2020.1280.13

3. BUJDOSÓ G. - CSEKE K. 2021. The Persian (English) walnut (Juglans regia L.) assortment of Hungary: nut characteristics and origin. Scientia Horticultruae 283.

DOI: https://doi.org/10.1016/j.scienta.2021.110035).

4. PINTEA, M. 2004. Nucul. Biologia reproductivă. Chișinău 365p.

5. PINTEA, M., BALAN, V. CIMPOIES, G. 2014. Following walnut footprints in Republic of Moldova. In Avanzato D. et al. Following walnut footprints (Juglans regia L.) cultivation and culture, folklore and history, traditions and uses. Leuven, International Society for Horticultural, Scripta horticulturae, vol. 17, p 203-211.

6. PÎNTEA, M., COZMIC, R., SACALÎ, N. 2015. Some biological and agronomical characteristics concerning walnut germplasm evaluation in the conditions of Rep. Moldova. Revista "Lucrări Ştiinţifice", Seria Horticultură: Congresul Internaţional "Solul şi hrana, resurse pentru o viaţă sănătoasă", Iaşi, 2015. ISSN$\mathrm{L}=1454-7376$, Print)

7. Pîntea M. et all.2021. Utilizarea durabilă și conservarea resurselor genetice: Studiu de caz.-Nucul (Juglans regia L.) în Republica Moldova. Chişinău ISBN:98.9975-56-887-6. 84p.

8. ÜNVER, H. SAKAR, E. SÜLÜŞOĞLU, M. 2016. Determination of pomological and morphological characteristics with fatty acid composition of high kernel ratio walnut genotypes. Erwerbs-Obstbau. Vol. 58, pp. 11-18. 